\title{
Lost and found: lessons from collaborative research with undergraduate students on the Lost Girls of Sudan
}

\author{
By Laura DeLuca (University of Colorado) \\ With assistance from Katherine Bruch, Lauren Rhoades, Lindsay Eppich, \\ Jordan Olmstead, and Jackie Holder
}

This article focuses on the challenges and rewards of working with undergraduate research assistants. The anthropological research project involves interviews and participant observation with Sudanese refugees living in the United States. Five undergraduates share their reflections as neophyte anthropologists. The audience for this article is primarily anthropologists and others interested in involving students in field-based research. Undergraduate students embarking on research under faculty supervision may be interested as well.

\section{Introduction}

The aim of this article is to highlight the pitfalls, difficulties, rewards and lessons learned from working with undergraduate researchers. The research assistants assisted with fieldwork and interviews of a group of Sudanese refugees. The five essays written by undergraduate researchers share the challenges and triumphs of their initial fieldwork experiences working with a group of Sudanese refugees popularly know as the Lost Girls of Sudan. The Lost Girls are the female children - now young women who fled the Sudanese Civil War that was reignited in 1983. Though the plight of Sudan's Lost Boys has been documented widely (Bixler 2005, Corbett 2001, Eggers 2006), a series of bureaucratic decisions left the Lost Girls virtually forgotten. After living in Kenyan refugee camps for a decade or more, a small group of these resilient young women have been resettled in Colorado. The close proximity of the Sudanese refugee group to the University of Colorado facilitated the opportunity for undergraduates to immerse themselves, if only briefly, in this unique community.

Several studies document the positive aspects of undergraduate-faculty research partnerships, including the role they play in student retention (Gregerman et al 1998) and graduate school preparation (Hartmann 1990). What is less often discussed is the personal experience of undergraduate-faculty research partnerships. Using a memoir style, five of my past undergraduate research assistants share the highs and lows of conducting anthropological field research for the first time. The essays were purposely left in a raw state with little editing so they could speak directly to the immediate experience of neophyte anthropology researchers. We felt that revisions would lead to more polished but less revealing insights.

As the research director, I start by describing the research itself and how the researchers were selected and funded. Later, I discuss the benefits and challenges of 
working with undergraduate research assistants. The main research question was how gender affected the resettlement process, but the undergraduate essays focus on the more personal side of the research process.

The undergraduates who worked with me on the Sudanese refugee project were recruited from my introductory course - ANTH 1150: Regional Cultures of Africa in which there is a unit devoted to African migration and refugees, with Sudan as a case study. During the semester, I share stories about my own experience conducting research with Sudanese refugees and make students aware of the possibility of working with me on this project. Potential research assistants come to my office hours and tell me after class of their interest in working on the Lost Girls project. I select research assistant candidates based on their writing and public speaking ability as well as their passion for the topic and future goals. In order to become official research assistants, these undergraduates must write essays and we submit a group application to the Undergraduate Research Opportunity Program (UROP) at the University of Colorado. This programme offers faculty-led team research and individual undergraduate student grants which pay 800 to 1,200 dollars for a semester of work. Most of my research students express their gratitude for being paid to do what they consider interesting work as opposed to the low-skilled service jobs available to undergraduates.

I make students aware of the fact that UROP grants are competitive and that there is no guarantee that our proposal will be accepted; in the cases where we receive funding the undergraduates are often appreciative. Their gratitude for my role in helping them secure meaningful paid work may explain the explicit flattery present in some of the essays. Some of the research assistants did reify the difference between themselves and me. At times I used this as part of building their motivation to become future anthropologists while at other times I discouraged this by treating the students more as colleagues. However, all of the students I worked with were paid by a faculty team grant, and hierarchy is built into the UROP structure since the grant is awarded to me and I am the designated supervisor.

\section{Letting go of your inner control freak: research with undergraduates}

My initial title for this article was "Letting go of your inner control freak: Conducting anthropological fieldwork with undergraduate research assistants". One of my anxieties about working with undergraduates involved the fear that they might make a mistake that would reflect poorly on the project and even jeopardise my ongoing research. My initial concerns revolved around issues of undergraduates maintaining confidentiality and following research protocol required by the university's Internal Review Board (IRB). Like many cultural anthropologists in the US, I find the biomedically-derived protocols of IRBs inappropriate when applied to humanisticallyoriented field research, yet I still felt responsible for upholding IRB rules.

Another challenge in relation to working with undergraduate researcher was how their lack of knowledge might reflect poorly not only on the project but also on how I have trained them. For instance, an undergraduate research assistant was conducting an interview with a local rabbi whose congregation was actively supporting the Lost Girls of Sudan; the rabbi had given a social action sermon on Rosh Hashannah 2004 that motivated many members of her congregation to work as activists for Darfur and 
to help resettle a group of Lost Girls of Sudan in Colorado. During the course of the interview, the rabbi began to discuss the genocide in Darfur and South Sudan and said "when we [Jews] say never again we are not talking about just Jews". The rabbi also talked about not standing idly by when bad things are happening to your neighbour. At the end of the interview, my undergraduate research assistant said to the rabbi "well there are genocides all the time all over the world so why focus on this one?" The rabbi pursed her lips, and then replied, "We Jews are very particular about the use of the term genocide." I was present at the interview and it was my impression that the rabbi thought the undergraduate was careless in her use of the term genocide. Though it was a learning experience, it was awkward and had the potential to reflect negatively on the research, but undergraduates are allowed to be naive and even ill informed at times.

Another difficult situation arose when an undergraduate researcher asked a Sudanese refugee named Nadai if she had a boyfriend. This question was not on the semistructured interview form, it was not a question approved by the human research committee. More importantly, it was not a culturally appropriate question to ask Nadai, a newly arrived 18 year old, because romantic relationships are considered very private in the areas of Kenya and Sudan where she had lived before coming to Colorado; even if she were to talk about a boyfriend, it would not happen with a relative stranger who was recording the conversation. The undergraduate student's question seemed potentially inappropriate to me but it would not be an unusual question for most American undergraduates at our university to ask each other; it may even be a normal way for them to establish rapport. Nevertheless, I wondered if Nadai felt uncomfortable. I was also concerned that the IRB might consider such a question a breech since it was not related to our proposed research. At first I viewed this question as a mistake and told her so during our weekly review meeting.

What I viewed as undergraduate missteps highlights the difficulties of taking responsibility for another researcher's interactions with informants in collaborative projects. However, it raises a further crucial issue about the nature of ethnographic work which would be lost if I simply dismissed these examples as just embarrassing mistakes by undergraduates. After all, anthropology's method is centrally about working in culturally unfamiliar environments. Therefore, allowing undergraduates the space to make awkward, embarrassing and even uncomfortable mistakes is part or the learning process. Being corrected and set straight by informants is one of the key ways in which ethnographers produce knowledge (as countless vignettes about embarrassing mistakes made even by experienced anthropologists attest). So what I initially framed as a limitation of undergraduate researchers may actually be a strength. The fact that undergraduate anthropologists are often able to be naive about things that their instructors take for granted means that they have the potential to bring a fresh, unique perspective.

The abovementioned student improvisations also speak to the process of training neophyte anthropologists and conducting research together over the course of a semester. Much of this process was shaped by external factors such as funding. For example, our UROP financial support lasted for one semester of work so it was necessary to train research assistants in anthropological methods and do the actual research in a 15 to 16 week period. My research assistants did not receive a grade or course credits for the research so their coursework remained a priority. UROP does have a brilliant policy of not paying students their final stipend until they complete their project, but the research is still fit into a relatively short period. This means that I 
spend the first few weeks talking about anthropological research methodologies such as participant observation and assigning short readings. (Most of the students are familiar with Sudan and refugee issues through taking my course.) In retrospect, it might have been useful to build in some methodological training and deeper discussion about issues of identity, difference, colonialism, and exoticising the other into the course. I would also urge UROP and other undergraduate research funders to consider longer time periods that allow for training before embarking on research. UROP could still pay the same amount of money but simply stretch it out over the course of a year. The first semester could focus on reading about anthropological methods, interviewing and ethnography. After reading and discussing the process of conducting research, undergraduates could slowly start to conduct practice interviews and then in the second portion actively begin research. This slower time frame is especially appropriate for ethnographic research and would enable students to learn about some of the subtler aspects of field research, analysis and representation and allow for a longer training period.

\section{Benefits of working with undergraduates}

Additional positive aspects of working with undergraduates on the Lost Girls project include their ability to establish rapport, their computer and photography skills, as well as assistance with more mundane work such as filing, checking out books, compiling and annotating bibliographies, and occasional assistance with transcribing interviews. For example, one of my undergraduate research assistants was a talented photographer and contributed photos of five Sudanese dancers wearing white body paint and ornate headdresses to an article that we published together. In some ways, my young female undergraduate researchers are in a better position to develop rapport with the Lost Girl refugee community because they are closer in age and life stage to my research subjects. In contrast, I am two decades older than most of the unaccompanied minor refugee women, making it culturally inappropriate for my Sudanese subjects to discuss some personal issues with me.

One less tangible positive aspect of working with undergraduate researchers is the satisfaction of training neophyte anthropologists who are often quite excited about doing fieldwork, reading anthropology, and writing about what they learn. For example, undergraduate research assistant Lindsay Eppich often exclaimed that doing research in the Sudanese community helped her discover her life passion and future career path. It is exciting to assist in the process of helping students realize their dreams. In addition, some of the undergraduates and I co-authored articles on our research, providing them with an opportunity to get published as an undergraduate (DeLuca and Bruch 2005, DeLuca and Eppich 2007).

Summarising the experience of working with undergraduate research assistants remains a challenge. Am I arguing in favour of or against working with undergraduates? Neither. Instead, I describe the experience of one particular project in which there were both positive and negative aspects of working with undergraduates.

\section{Overview of the essays}

In the first essay, Katherine Bruch describes how her shyness shaped her research experience. Lauren Rhoades writes about attending an Obama celebration party in the Sudanese community as part of her field research. Lindsay Eppich writes about how 
undergraduate research motivated her to study abroad so she could gain a greater understanding of the refugee situation in Kenya, where the Lost Girls lived in Kakuma refugee camp and then a Catholic mission compound before coming to Colorado. Jordan Olmstead writes about becoming friends with a research subject, and Jackie Holder discusses research and reciprocity and how she offered to assist one of her informants with maths even though it is not Jackie's strength.

\section{Reflections on my first fieldwork experience (by Katherine Bruch)}

Looking back on my first anthropological research experience in the spring of 2005, I realize how shy I used to be. I was eager to learn more about anthropological methodology, and excited by the prospect of engaging in participant observation fieldwork, but I was also incredibly intimidated. Initially I spent a lot more time observing than participating. Reading about the turmoil in Sudan and everything the "Lost" Boys and Girls had been through only added to my trepidation in interviewing them about their resettlement process. Realizing all of the trauma and suffering they had already experienced in Sudan and Kenya, as well as the challenges that they would face as refugees in the United States, I wondered how I could possibly connect with them in an empathetic and yet substantive way. Additionally, interacting with American volunteers from the non-profit organisations and religious groups involved in the Sudanese resettlement process presented its own obstacles, as many of the volunteers were unofficial "gatekeepers" for the Sudanese community.

Not having any prior connections to Sudan besides my anthropology professor, Dr Laura DeLuca, and an introductory course on different cultures of Africa I had taken with her the previous semester, I wondered how I would be received in the Sudanese community as I attended my first event: a 2005 Sudanese church service celebrating the anniversary of the arrival of the first group of Lost Boys to Denver, Colorado, three years earlier. One month prior to attending this event I had eagerly accepted Dr DeLuca's offer to work as her undergraduate research assistant, but suddenly on the drive from Boulder to Denver I was getting cold feet. What would I say? What questions would I ask? Looking down at the spiral notebook I had brought for recording my "observations", I wondered if donning a white lab coat could have made me seem any more presumptuous or intrusive. Thinking back to a class discussion about Marcel Mauss' (1990 [1950]) book The gift, and his theory of reciprocity, I just hoped that eventually I would have something to offer to the Sudanese community in return for the notes and observations I would be taking.

Walking into the Episcopal chapel on Washington and $14^{\text {th }}$ Street in Denver, I was overwhelmed by the number of people I saw, well over 100, all of whom had come dressed in vibrant African colours and expressions to match. Temporarily forgetting about my apprehensions, I watched as friends and family embraced each other on the celebratory occasion. The atmosphere seemed surprisingly lighthearted. Listening to the exchange of greetings followed by a Christian mass conducted in Dinka, Juba Arabic, Swahili, and English, I felt as though I could be standing in a Sudanese church in South Sudan before all of the violence had broken out. Afterwards, at the reception, I was surprised again by how gracious and approachable everyone was, in spite of all they had been through and in spite of the fact that I was an outsider carrying a notebook. Instead of seeing me as threatening they welcomed me to join in the celebration. Without even knowing it, their kindness and hospitality made it easier for me, and my shy demeanour, to relate to them (even though in theory as the 
anthropologist I was the one who was supposed to facilitate that process). This humbling experience, in turn, helped me find a comfortable balance between my role as a participant and observer.

Throughout the course of the project I continued to attend various Sudanese events, but as our project developed Dr DeLuca and I shifted our focus from the Sudanese refugees to the volunteer groups involved in their resettlement process. As a result, we started spending more time attending non-profit meetings and gatherings organised by volunteer organisations assisting the Sudanese refugees. Interacting with these nonprofit professionals and volunteers offered a completely different participant observation experience. In general the volunteers tended to be more guarded. I remember one refugee resettlement agency even denied us permission to interview members of their organisation. Another challenge of working with the volunteers was gaining their approval of our research in the Sudanese community. Some of the volunteers who were especially close to the Sudanese youth, and thought of them as their own children, acted as gatekeepers wanting to protect the vulnerable community. In response we tried to make the gatekeepers, or pseudo-guardians, feel comfortable by explaining the nature of our research, our objectives, and the steps we would take to ensure anonymity on sensitive issues.

Reflecting on my initial experience with participant observation fieldwork, I realize how valuable it was for me to have that experience so early in my undergraduate career. While conducting anthropological fieldwork as a freshman proved slightly intimidating, it also helped me discover and work on my own personal challenges and strengths. In some ways I discovered that my shyness did not work as well with the American volunteers, but in other ways I saw that it could help me function as a keen observer and good listener in the Sudanese community. Dr DeLuca also reminded me that my quiet, demure personality in some ways made it easier for me to connect with Sudanese community members who often value such traits, especially in women. Spending less time participating and more time observing, I was able to notice subtle details, such as tensions between individuals, without directly influencing the dynamic or conversations between people.

Working with Dr DeLuca also helped me understand the benefits of collaborative teamwork-style research. Allowing me to function as her research assistant and fieldwork partner I could see that her research strengths balanced out my research weaknesses and vice versa. Dr DeLuca's personal background and interest in Africa, as well as her keen networking skills, helped counter my relatively minimal knowledge of the region and more reserved personality. She also served as the crucial link to the Sudanese and volunteer communities we studied. As a newcomer I, in turn, offered a fresh perspective on the situation while my observational awareness allowed Dr DeLuca to be more personally involved in the two communities.

All of these insights, as well as several others that I gained from my eight months on the project, undoubtedly helped transform me into a more balanced researcher, student, and individual. For this, I am indebted to Dr DeLuca for her wisdom as my mentor and her generosity in sharing a piece of her research project with me, to the Undergraduate Research Opportunities Program at the University of ColoradoBoulder for providing me with funding, and to the Young Sudanese community in Colorado whose warm-hearted culture and hopeful outlook humbled me. 


\section{Victory dance for Obama: Sudanese refugees celebrate (by Lauren Rhoades)}

As I opened the door to the Broker Inn hotel in Boulder, Colorado, USA, I felt as if I had entered a completely different world from that of Buckingham Hall, my University of Colorado dormitory only a few miles away. The cold November air outside was replaced with the warmth and festivity generated indoors. Tall Sudanese men in suits towered above the crowd, Sudanese women in gowns and traditional African prints chatted in groups, and laughing children weaved through the crowd, skillfully dodging waiters who carried trays laden with fruit and samosas. The room was brimming with happiness and excitement, a mood appropriate to the occasion: the Sudanese community's celebration of Barack Obama's victory in the presidential election.

I was among a number of guests from the Colorado community who attended the victory gala. At the time, I was assisting anthropology professor Laura DeLuca with her research on the Sudanese "Lost Girls" community in Boulder. I went to the celebration in solidarity with some of the Sudanese immigrants living in Colorado and the organisations that assisted them. Not quite knowing what to expect, I was stunned by the overflowing rooms of people, the election-themed decorations, the tables of pamphlets from charitable organisations, and the artwork by members of the Sudanese community.

I edged my way cautiously through the crowd toward the buffet table filled with warm samosas (meat pies), kisra (Sudanese bread made with fermented dough), and beef curry. I was overwhelmed with smiles and conversations about the election. Did you vote? Yes, did you? No, but I will in four years when I get sworn (become a US citizen). Did you watch the election? Of course! The room buzzed with energy and excitement.

Once my heaping plate could hold no more, I found an empty chair at a nearby table. I felt out of place as the only white non-Sudanese girl out of the eight or so others who were laughing and speaking a language that I did not understand. As I sat there quietly eating and observing, I wondered if this was a sample of what it felt like to come to the United States from Sudan - unaccustomed to hearing and speaking the language, following the cultural customs, having a different skin colour from the majority. But even this small act of stepping out of my comfort zone would never allow me to comprehend the refugee experience and cultural shock that the guests at my table had lived through. How could I ever begin to empathise with having to live on rationed food in the midst of an overcrowded, windswept refugee camp in the Kenyan desert? How could I understand what it would be like to live thousands of miles away from home, family, and friends, some of whom may have been killed by disease or malnutrition or war? How could I find the strength to begin a new life, work multiple jobs, or navigate an educational system in one of the world's wealthiest nations? How would I fit in?

I looked around the room at the men and women absorbed in conversation, recounting stories, eating, laughing, and smiling. I felt separated by a wide ocean of experience, even though every Sudanese guest I had talked with was lively and inclusive, betraying no trace of the hardships he or she had endured.

All of a sudden, everyone at my table stopped talking and focused their attention on the polished wooden dance floor in the middle of the room. In light of the night's 
festivities, a group of Sudanese women who called themselves "The Flamingo Girls" had prepared a performance. They strutted into the room, vibrant in African print skirts with bangles on their ankles and wrists. The women sang a song in English and Swahili, while we all sat mesmerised, listening to the harmonised lyrics "we are so happy on this day" reverberate around the room. Next they performed a traditional dance. They moved their bodies, stomped their feet, and clapped their hands rhythmically, the bangles they wore echoing in unison. I had never seen a dance that was such a pure outward expression of joy. It was as if each movement embodied the electric energy of our celebration.

Captivated by the music and dancing, there was no need for me to feel like an outsider. That night we were brought together to celebrate the election of the first black man to the American presidency - a victory that spanned generational, racial, national, and experiential differences. Yet to the Sudanese community in the US and their American friends and allies, this presidential victory was symbolic of every personal triumph over hardship, oppression, and misfortune. The struggles of daily life continued - there was paying the rent and taking care of children, getting a promotion, turning in a research paper on time - yet we all rejoiced in our hopes for the future. Filled with music and happiness, all of us clapped with the beat, smiling uncontrollably as The Flamingo Girls sang and danced for victory.

\section{Watching "Tyra" in Kenya (by Lindsay Eppich)}

When I stepped off the plane in Kenya in the humid air, after 50 hours of travelling with 14 total strangers, I felt like I was right where I was supposed to be. I had decided to study abroad with the School for International Training (SIT) in Kenya after working for the previous two years with Sudanese refugees, particularly focusing on the "Lost Girls". In collaboration with anthropology professor Laura DeLuca, I had worked closely with Sudanese refugees and found that I had learned more outside of the classroom through this research than I could ever have imagined. I became engrossed in my work and decided to take it a step further through studying abroad. I applied to live and study in Kenya for a semester, hoping to spend a month working in the Sudanese refugee compound where many of the Sudanese women I worked with in Colorado had spent a significant period of time before they were resettled to the United States. It was my chance to see the other side of the research I had been working on with Dr DeLuca in Colorado and really understand the lives these Sudanese women had left when they came to the United States.

The opportunities I had as an undergraduate researcher prior to my arrival in Kenya made my study abroad experiences much richer and allowed me a much deeper experience. I was able to jump into my independent study project with SIT and learn without hesitation or fear. After several months of studying Kiswahili, Kenyan culture, and travelling around the country, we were sent on our own to do a month's worth of independent research. I was ready. Finally a chance to use the skills and tools I had developed as an undergraduate researcher in the US and apply them in a much more challenging and foreign anthropological setting.

I travelled to Nairobi and stayed within the walls of a refugee compound run by a German nun who was well known in the Sudanese community for her humanitarian work. I helped the refugees by using the typing and computer skills we as privileged American students take for granted. Though I am not an avid television fan in the 
United States, in Kenya I spent many afternoons watching Tyra, the American television show favoured by the Sudanese girls. As they watched they thinly sliced bright green collard greens in preparation for the evening meal. Sitting crowded together with a dozen Sudanese women in a small room with the sounds of Tyra talking about the latest US fashion was a way for me to relate to and learn about the incredible women I had travelled half-way around the world to try to understand. We sat and braided each other's hair and talked about topics that would never have been possible to bring up in another setting. We talked about dating, American culture, what they remembered of their childhood, problems that arose in the refugee camps, as well as their hopes and dreams for the future. In this setting I was a friend. A bit of a conflict for a budding anthropologist at times, but a situation I learned to understand as an undergraduate researcher in the US.

I would never have imagined that all the way across the world in Kenya, Tyra would have brought me so close to women like Grace Deng and allowed me to learn about her daily concerns through this out-of-the-norm form of participant observation. The challenges inherent in doing anthropological work were something I started to become aware of working with refugees in Colorado, but they became even more obvious in Kenya. My undergraduate research in the US helped to prepare me for understanding the situation of Sudanese refugees in Kenya, yet I would never have imagined that I, a white girl from Durango, Colorado, would learn so much about Sudanese refugee lives by watching a pop-culture, American TV show with them on a regular basis. Sitting in that room with the TV on we were just women. Women in a world that is full of possibility, challenges, and daily confrontations that we were all struggling to relate to.

\section{Becoming friends: research and loneliness (by Jordan Olmstead)}

In my freshman year I took an anthropology course on Sudan and the conflict in Darfur. As part of the service learning requirement I worked with a non-profit group that assists female Sudanese refugees in Colorado, US. When the end of the semester came, I wanted to continue learning about and working with the girls. So I applied for a research assistantship from UROP (the Undergraduate Research Opportunity Program) with Dr DeLuca, the professor of the class. My role was to interview some of the Sudanese Lost Girls about their experience to help with the research for a book that Laura DeLuca was writing on them. The experience is one I will carry with me always, and provided me with life long memories like the following one.

I had already interviewed a few of the girls when I finally got a call back from Nakang. She had been hard to get hold of, and even harder to get an interview with. This interview would be different too as we were meeting at night instead of during the day, as with the other girls. I climbed the steps of the brightly coloured apartment buildings in the complex where the refugee women lived and knocked at the door. I heard a shuffle of footsteps from inside and the door opened. There stood a petite young African woman with bright beaming eyes. She quietly led me to the table where we would do the interview, and in Sudanese fashion asked if there was anything she could get me to drink or eat, and made sure I was comfortable. No one else was home; it was just me and her in the apartment.

There was something different about Nakang. Of course each of the other girls I had interviewed was amazing and unique in her own way, but something about Nakang 
made me listen as I had not yet done before. The interview went smoothly, and rather quickly, which was great because I had a lot of homework to do. But just when I was about to call it a night, Nakang just kept talking; and I could not stop listening. Something told me to stay, so I did. She started asking me all kinds of questions, about school, working, and life in the United States. I could not help but try and answer all her questions. We talked about her work as a maid in a luxury hotel and the people she worked with. We talked about her aspirations for more education, and the difference she wanted to make in the world. She possessed so much optimism and hope for the future, yet she had an incredible and beautiful loneliness about her; a kind of longing that held me there for a good two hours.

On some level we shared that same loneliness, and I felt a connection with her that I have felt with very few people. Our conversation is one I will always remember. I believe there are people who make lasting imprints on your life, people you will never forget even if you just met them for an instant; Nakang was one of those people. Just a few days later, I was walking up another flight of stairs to do another interview. We were making small talk and I told her that I had interviewed Nakang a few nights before. She replied, "Oh yeah, Nakang said she had a friend coming over that night," and was very excited. I had never met Nakang before, yet we were friends before we had even met.

\section{Me a maths tutor? Research and reciprocity (by Jackie Holder)}

As a researcher for Dr Laura DeLuca, my role was to conduct interviews with several female Sudanese refugees who had arrived in Colorado in the past two years. I worked at getting to know them through participant observation - mostly attending refugee celebrations - and by conducting semi-structured interviews. During one interview a young Sudanese woman named Nakiru told me about her experience during her first semester at a Colorado community college. We discussed the vast differences between American schools and those in Kakuma refugee camp in Kenya where she had lived for six years. Nakiru was particularly adamant in relaying how extensive the amount of homework was that she was now being presented with and that she had never before been required to finish so much reading, writing and arithmetic before class. Nakiru went on to lament her difficulties finishing the 100+ problems she had as maths homework (she said they call it "maths" in Kenya as opposed to the US "math"). I offered to stop by the next evening to help and she accepted.

This may not have been the wisest pairing for her since maths just may be classified as my worst subject. Locating the section of my brain that had happily filed away my knowledge on maths, specifically algebra, was challenging. We stumbled and stalled through problems but slowly found an even rhythm and I somehow, miraculously, managed to assist her. What made more of an impression on me though, besides my rebirth into the world of trinomials and the Quadratic Formula, were Nakiru's study habits. I took note of her blaring reggae music, the low lighting, and the various other girls - Atiol and Achulo - stomping in and out of her apartment to use her computer. It was not ideal, in fact, it was downright impossible to focus. Not wanting to insult her I said nothing about the environment she had created for her study space.

What I realized from this experience was that, most likely, no one had ever taught her how to study. I have taken for granted the years spent instilling effective study habits 
by my parents and teachers and that over time I acquired the skills that are necessary to tackle homework successfully. She has been thrown into this world without preparation and forewarning of the responsibilities western schooling places on its students.

Besides homework dilemmas Nakiru, and the other Lost Girls, face a multitude of challenges as they try to create a new identity as resettled Sudanese women and integrate into American society. In each interview, the girls shared stories about some of the many challenges they faced. Whether it was wrestling with applications for the SAT (Scholastic Aptitude Test - an American college entry exam), their shock in realizing that Colorado could be as hot as Africa, deciphering the scandalous dressing habits of American girls, or their initial fear of snow; they all spoke about these difficulties as comic obstacles, ending each story with a cheerful laugh.

I found the Sudanese refugee women I interviewed to be exceptionally inspiring because, though having lived through some of the most horrific survival challenges in modern-day war-torn Africa, these so-called Lost Girls view their future with optimism. When one of the girls named Loriho had just arrived in the United States she heard news from Africa that her mother and father were alive. This was the first Loriho had heard of them since they had been separated when she was seven years old and she had assumed they were killed. The mix of elation about locating them and the sorrow that she was still worlds away from them, as devastating as it was, did not cause Loriho to lose focus on her goals. She continues to navigate the vacillating winds of resettlement with resolve.

My favourite thing one of the girls said in reference to her future goals, which I believe embodies the determination of many of the Lost Girls, was when Nyanath, a woman from Bentiu, said: "God if you open for me the way, I am going to try my level best because I have so many things to do."

I have carried my interest in the inequalities of refugee resettlement to my graduate studies at the University of Denver, where I am now in the master's programme in the Graduate School for International Studies (GSIS) with a focus on human rights.

\section{Conclusion: power, colonialism, identity, and Sudanese women as actors}

The five essays offer reflections on the fears, challenges, and thrills experienced by undergraduate researchers doing anthropological fieldwork for the first time. At times almost every research assistant shared frustrations about the interview process - how it was hard to set up interviews with the busy Sudanese women and how once they set up interviews there were often miscommunications, especially about time. One undergraduate researcher at the end of the three month research period said, "I finally figured out that if a Sudanese dance event or dinner is supposed to start at 6 that I should show up at 7 and I might still be early!"

Though the essays are engaging and fresh, at times there is also a tendency to fetishise difference and to refer to their informants monolithically as "the Sudanese". I inadvertently contributed to this tendency by using this term myself - often for ease of description - in class. Yet, terms like "the Sudanese" or "the Trobriand Islanders", "the Yanomami" or "the Samoans" overlook the internal diversity of these groups. Adding to this is the fact that many of my students are drawn to anthropology because 
they want to learn about groups that are different from themselves. (In the programme where I teach anthropology, most of the students are white, middle or upper-middle class, from suburban Denver or various smaller cities in Colorado as well as Chicago, southern California or the East Coast). Many of these students are initially drawn to anthropology because of an interest in the exotic other. Several undergraduates mention the popular author Joseph Campbell as a source of inspiration in their pursuit of anthropology. Before taking anthropology, many of my students expect their studies to focus on the kinds of exotic tribes featured in National Geographic, an American institution that according to Collins and Lutz (1993) often teaches us more about our own culture than those of the distant tribal groups it features. A significant portion of my students are drawn to our Rocky Mountain campus partly because they are interested in activities such as climbing, hiking, snowboarding and skiing; cultural anthropology often appeals to these adventure-oriented students who view exotic fieldwork as an extension of their interest in the outdoors .

In retrospect some of the teaching materials I have used may inadvertently have promoted an exoticising perspective. For example, in ANTH 1150, I show Robert Gardner and Hilary Harris's 1971 film The Nuer with its dramatic scene depicting gaar - a rite of passage in which young boys must prove their bravery by not flinching during forehead scarification. These teenage Nuer boys are cut so deeply on their foreheads that the audience sees blood spurt out and their skulls are revealed. Undergraduates wince and even hide their eyes but are also fascinated by the exotic, brutal scarification. Discussing these representations within the context of colonial history and issues of identity change may provide a more thoughtful context for moving beyond the shocking exotic factor of the film. Though I did assign Shandy's more up-to-date book Nuer-American Passages (2007), which argues that refugees are actors not simply victims, I could have reinforced her theoretical perspective more deeply in the classroom.

Finally, some of the undergraduate essays in this article inadvertently portray Sudanese research participants as research objects instead of as active human subjects. This tendency is troublesome given anthropology's early portrayal as a "handmaiden of colonialism". In retrospect, I might have been more attentive to this aspect of undergraduate representation. One of my biggest challenges as a project director was to slow down and pay attention to research dynamics instead of forging forward in the desire to complete more interviews and accomplish more ethnographic work.

Christine Abuba Nakwa, Rose Inne Lokwang and Mary Ingiria Atilio are three Sudanese female undergraduates who joined the research team in May 2009. The inclusion of these Sudanese researchers may help establish the Sudanese women as actors in their own right, and as active participants in (and shapers of) the research process. Even before Sudanese researchers joined the team, our informants actively shaped the research process - for example, Lonyaromoi refused to be interviewed, saying she was not interested in talking about her life again (many journalists have also interviewed this group). In my initial sessions with our Sudanese researchers, we discussed how Rose Inne Lokwang and Mary Ingiria Altilio felt when they were interviewed by the earlier undergraduate researchers and Lokwang said: "Why, why? I want to know why they are doing this research." 


\section{References}

Bixler, Mark. 2005. The Lost Boys of Sudan: An American story of the refugee experience. Athens, GA: The University of Georgia Press.

Corbett, Sara. 2001. The Lost Boys of Sudan: The long, long, long road to Fargo. The New York Times. 1 April.

DeLuca, Laura and Katherine Bruch. 2005. Lost and found? Fragmented fieldwork amongst Sudanese refugees in Colorado. Anthropology News 46(6), 32-33.

DeLuca, Laura and Lindsay Eppich. 2007. It takes two hands to clap: Sudanese refugee women contribute to conflict resolution in Sudan. Anthropology News 48(6), 38-39.

Eggers, Dave. 2006. What is the what: The autobiography of Valentino Achak Deng. San Francisco: McSweeny's.

Gregerman, Sandra R. et al. 1998. Undergraduate student-faculty research partnerships affect student retention. The Review of Higher Education 22(1), $55-72$.

Hartmann, David J. 1990. Undergraduate research experience as preparation for graduate school. The American Sociologist 21(2), 179-88.

Lutz, Catherine and Jane Collins. 1993. Reading National Geographic. Chicago: University of Chicago Press.

Mauss, Marcel. 1990 [1950]. The gift. London: Routledge.

Shandy, Dianna. 2007. Nuer-American passages: Globalizing Sudanese migration. Gainesville, FL: University Press of Florida.

\section{Acknowledgements}

Thank you to the following people and institutions for supporting research and writing about the Lost Girls of Sudan - Joan Gabriel and May Penuela at the University of Colorado-Boulder, the Undergraduate Research Opportunity Program (UROP), Willem Van Vliet, Director of the Children, Youth, and Environments (CYE) Center, the Global Studies Residential Academic Program (G-RAP), the Center for Humanities and Arts (CHA) and the Institute for Ethics and Civic Engagement (IECE) at the University of Colorado-Boulder, as well as Colorado Humanities and the School for Advanced Research (SAR) in Santa Fe, the Maria Rogers Oral History Program of the Carnegie Branch Library for local History, and the Radcliffe Institute for Advanced Study's Oral History of Women in America project at Harvard University.

\section{About the author}

Laura DeLuca teaches anthropology at the University of Colorado and is a visiting scholar at the Children, Youth and Environments (CYE) center. She has been conducting research on Sudanese refugees for six years. In 2005, she was invited to participate in the Sudan Field School held in Rumbek, Sudan, and in August 2009 will visit Juba, the southern capital. Laura DeLuca is currently writing a book about the Lost Girls of Sudan with Leah Bassoff and is collaborating with documentary 
filmmaker Deborah Fryer on this topic. As part of a grant from the Radcliffe Institute for Advanced Study, she is working with Sudanese researchers to collect oral histories that will become part of the Schlesinger Library's History of Women in America collection. She can be contacted at laura_m_deluca@yahoo.com. 